\title{
A patient with chronic dyspnea and episodes of paroxysmal atrial fibrillation in the presence of a right atrial mass
}

Georgios Papaetis ${ }^{1}$, Andreas Andreou$^{1}$, and Stylianos Karvounaris ${ }^{1}$

${ }^{1}$ Affiliation not available

December 1, 2020

\begin{abstract}
Lipomatous Hypertrophy of the Interatrial Septum (LHIS) is an unusual condition that can be presented as a mass-like bulge that typical spares of the fossa ovalis. We describe a 73-year-old overweight woman with dyspnea on exertion and two episodes of paroxysmal atrial fibrillation for the last eight months. A big sessile mass was detected in the interatrial septum measuring $3.7 \times 4.7 \mathrm{~cm}$ during transesophageal echocardiography. The patient underwent resection of the mass and pericardial patch reconstruction of the defect with significant improvement of her clinical status during the follow-up period. The histopathological analysis suggested LHIS.
\end{abstract}

\section{Hosted file}

Papaetis, manuscript rev.pdf available at https://authorea.com/users/380290/articles/496351a-patient-with-chronic-dyspnea-and-episodes-of-paroxysmal-atrial-fibrillation-in-thepresence-of-a-right-atrial-mass

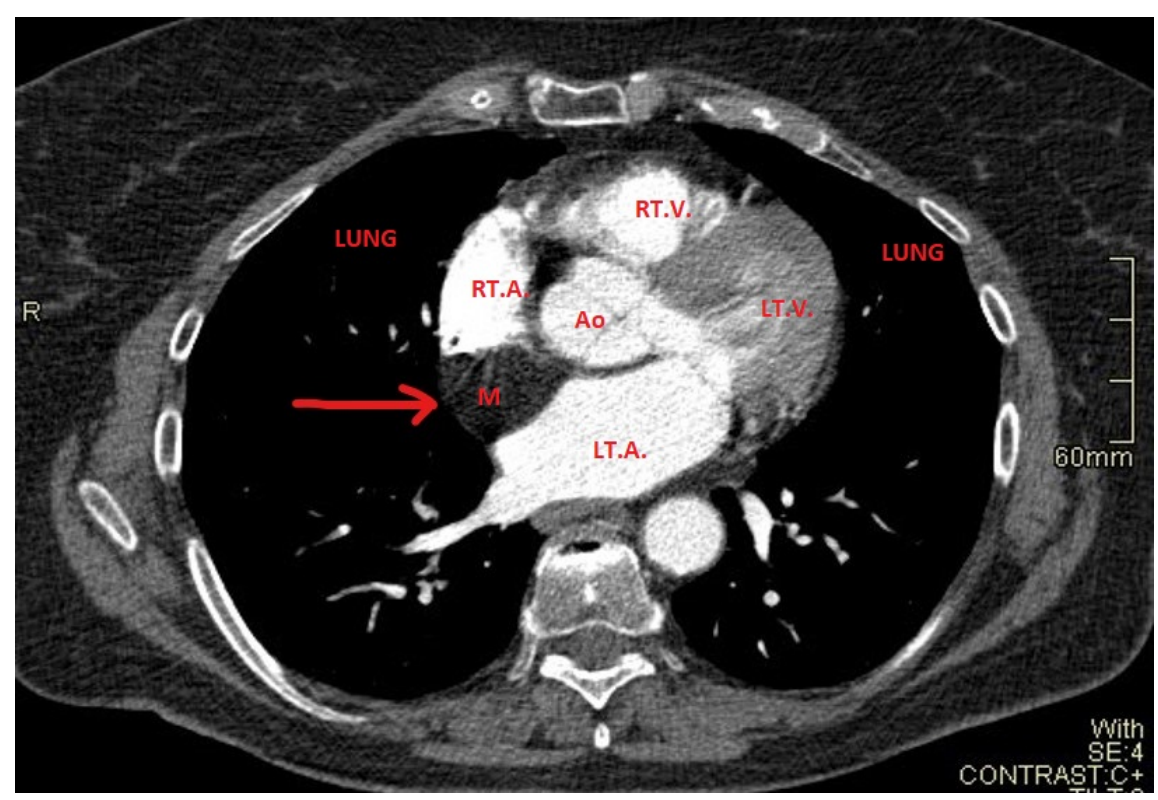



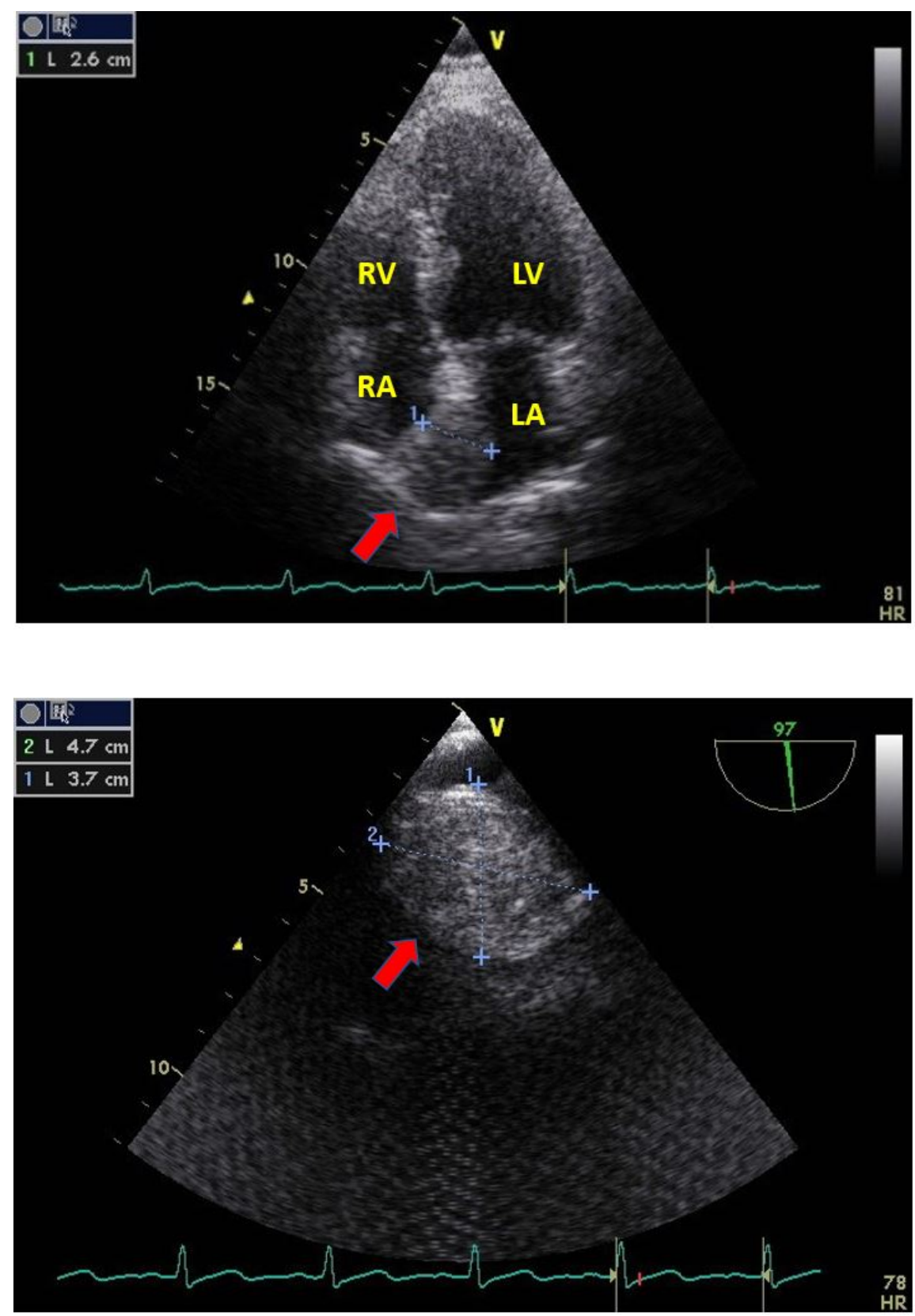